\title{
Preparing Faculty for Teaching a MOOC: Recommendations from Research and Experience
}

\author{
Stephanie L. Richter and Murali Krishnamurthi
}

\begin{abstract}
Due to the increasing popularity of Massive Open Online Courses (MOOCs) more faculty and institutions are exploring MOOCs. Faculty often seek help from campus units such as Faculty Development centers to handle the complexity of factors involved in planning, designing, developing and delivering MOOCs. As a result, Faculty Development centers should be ready to prepare faculty for teaching a MOOC. In this paper, a number of recommendations, based on research and experience, for faculty development staff to follow in helping faculty plan and design a MOOC, and organizational issues to consider are summarized.
\end{abstract}

Index Terms-Faculty development, instructional design, MOOC.

\section{INTRODUCTION}

Traditionally, Faculty Development centers or Teaching and Learning Centers have focused on supporting teaching activities within their respective institutions. This has been challenging enough, given the limited resources, diversity of disciplines, and variety of teaching approaches and scenarios that are currently popular: large lectures, small discussion sessions, seminars, active learning, collaborative learning, experiential and service learning, as well as face-to-face, blended, flipped, and online classrooms, to name a few. The rising institutional pressure on many campus to become involved in the world of massive open online courses (MOOCs) increases the challenge, particularly given that only a few institutions have experience offering them (a recent survey reported $13 \%$ of institutions offer MOOCs [1]).

As faculty often seek Faculty Development centers' support on teaching-related activities, it is important for Faculty Development centers to be aware of the issues related to preparing faculty to teach in this new paradigm and be successful in meeting institutional goals. This paper summarizes the recommendations of Northern Illinois University's Faculty Development and Instructional Design Center for other Faculty Development or teaching and learning centers in supporting faculty who plan to teach in the MOOC format. These recommendations come from a review of available literature and web resources on planning and delivering MOOCS, participating in numerous MOOCS on a variety of platforms, and the experience of launching the "Perspectives on Disability" MOOC in August, 2013, and

Manuscript received August 25, 2013; revised December 17, 2013.

S. L. Richter is with the Faculty Development and Instructional Design Center at Northern Illinois University, DeKalb, IL 60115 USA (e-mail: srichter@niu.edu).

M. Krishnamurthi is with the Faculty Development and Instructional Design Center and Department of Industrial and Systems Engineering at Northern Illinois University, DeKalb, IL 60115 USA (e-mail: mkrishna@niu.edu). will benefit faculty developers and faculty everywhere. Lessons learned from the outcomes of the course will be shared at the conference and in subsequent publications.

\section{HISTORY OF MOOCS}

Whereas the concepts and techniques that support Massive Open Online Courses (MOOCs) are not new, it is fair to say that MOOCs have made a sudden appearance in the world of education. In November, 2012, The New York Times declared 2012 to be "The Year of the MOOC" [2] and MOOCs were listed among the top ed-tech trends of 2012 [3]. The New Media Consortium Horizon Project, which tracks and predicts emerging trends in educational technology, included MOOCs in the 2013 Higher Education edition of the NMC Horizon Report [4] for the first time at the "One Year or Less" horizon to adoption. That MOOCs bypassed the "Two to Three" and "Four to Five" year adoption horizons demonstrates how quickly MOOCs have risen in popularity.

It is difficult to determine when the MOOC phenomenon began. The term "MOOC" was coined in 2008 to describe the Connectivism and Connective Knowledge course (CCK08) taught by George Siemens and Stephen Downes that fall semester [5]. Roughly 2200 participants registered in that course [6], which makes it the first massive open online course to bear the name, but not necessarily the first open online course. Downes credits two others, David Wiley and Alec Couros, for providing the inspiration to offer course instruction openly online. MOOCs gained popularity in 2012, with the launch of Udacity, Coursera, and MITx, which later the same year became EdX [7].

\section{RECOMMENDATIONS FOR PREPARING FACULTY}

Others have written about tips for faculty who are considering offering a MOOC and questions to ask when designing a MOOC [8], [9]. This paper differs because it focuses on the role of Faculty Development centers in the support and preparation of faculty who teach MOOCs rather than on the faculty directly. In addition, this paper incorporates recommendations from the emerging research on teaching and learning strategies in MOOCs.

The recommendations fall into three categories: Before Planning a MOOC, Designing a MOOC, and MOOC Considerations. These recommendations are summarized in Table I.

\section{A. Before Planning a MOOC}

The first recommendation for Faculty Development staff who may need to support a MOOC development initiative is to participate in several MOOCs on multiple platforms 
offered by a variety of providers. This will help to gain astrategies of existing MOOCs. By fully engaging with the course (not just "lurking" to look around), it is also possible to learn about the challenges and expectations of students who participate in MOOCs.

TABLE I: RECOMMENDATIONS FOR FACULTY DEVELOPMENT CENTERS SUPPORTING MOOCS

\begin{tabular}{ll}
\hline \hline Before planning a MOOC & Participate fully in several MOOCs on a variety of platforms \\
& Research emerging learning theories \\
& Research legal, ethical, and institutional issues associated with MOOCs \\
\hline Designing a MOOC & Choose an appropriate topic and determine the target audience \\
& Build a team \\
& Plan the development \\
& Identify outcomes and drive course design from them \\
& Design communication plan and community development strategies \\
& Plan assessments for a massive audience \\
& Determine technology for MOOC delivery \\
& Consider participant motivations \\
& Seek out funding \\
POOC Considerations & Promote the MOOC \\
& Research on learning in MOOCs \\
\hline \hline
\end{tabular}

Secondly, Faculty Development staff should explore new and emerging learning theories related to MOOCs. A majority of faculty development staff and instructional designers are most likely familiar with classic learning theories, including Behaviorism, Cognitivism, Constructivism, and other theories. However, some theorists argue that these are insufficient for the complexity of massive communities and how learning occurs in an increasingly digital world. For example, many MOOCs are based on Connectivist learning principles [10]. Others have examined MOOCs through the lens of chaos and complexity theory [11]. Since connectivism, chaos theory, and complexity theory are not commonly explored in all disciplines in higher education, it would be beneficial for faculty developers to know about them before beginning a MOOC project.

It would also be beneficial to research the legal and ethical considerations surrounding MOOCs before developing one. Some examples of legal considerations include awarding of course credit, copyright of materials used for instruction, intellectual property rights to materials developed for the course and of student submitted work, censorship of MOOC participants, agreements with technology platform partners, faculty governance issues, and university policies related to launching a new instructional delivery approach at the institution. It is highly recommended that Faculty Development centers research these concerns prior to developing a MOOC and discuss them with academic administrators, faculty governance personnel, and legal counsel at their institutions. Otherwise, misunderstanding about the MOOC can result in backlash or opposition [12], [13].

\section{B. Designing a MOOC}

Once a faculty member decides to deliver a MOOC, there are a number of opportunities for Faculty Development centers to leverage existing expertise to prepare and guide the faculty member. Most of these recommendations take advantage of project management, instructional design, and instructional technology skills.

Faculty may require guidance with choosing an appropriate topic for a MOOC. The topic should be one the faculty member has expertise in and he or she is passionate about [8]. From examining courses offered through common MOOC providers, it seems that some MOOCs are based on common university courses, which was the case for
Perspectives on Disability [14] and many of the original MOOCs [15], but others appear to be topics that are developed solely as MOOCs (like the "moocmooc" [16]).

Another essential aspect of selecting a topic is determining the target audience for the MOOC [8]. This is beneficial because it helps to determine if there will be sufficient demand for the MOOC to warrant offering it. Identifying the audience also allows for a detailed learner analysis, which is often a component of the instructional design process [17]. Once the learner characteristics are identified, the course can be designed accordingly.

Before the course begins, some learner characteristics will have to be inferred from common demographics of MOOC students. Some studies [11], [18] found students to be diverse in terms of age, geographic location, and professional background. In many courses, the majority of students already held university degrees [18], [19] or were professionals working in the field of the course [11], [20]. Naturally, these are isolated studies and do not necessarily allow for inferences about other courses or topics. However, it shows that one essential task of Faculty Development centers and instructional designers is to research student demographics before helping faculty design a MOOC course and to survey the actual MOOC students.

Several institutions and individuals who have delivered MOOCs recommend building a team for the MOOC [8], [9], [18]. This could be a team for developing the course, for facilitating the course, or for a closer co-teaching relationship. While there was a single primary instructor for Perspectives on Disability MOOC, a team approach was essential for its design and development. The partnership between faculty member, Faculty Development center, developers, and student advisors ensured a high-quality final product.

Instructional designers and other Faculty Development center staff generally have project management experience and background, which is a valuable skill on a project of the magnitude of a MOOC. Some faculty members may not have experience organizing, tracking, and balancing the many phases of a system development project, participants, and assetsinvolved in such a project. Beginning the project by helping to develop project timelines for design, development, promotion, and evaluation of the MOOC is an important step.

In addition, while faculty members are experienced at designing content and delivery for their face-to-face course, they may require additional assistance when designing for an 
unfamiliar format. Faculty Development centers can provide guidance on online teaching and learning strategies, media design practices, and community learning models as well as advise on formal instructional design practices.

When designing the course, it is recommended to begin by determining the outcomes of the course [8], [9]. Consider what participants will learn as a result of the MOOC, or what desired results of the MOOC are. For Perspectives on Disability MOOC, the outcomes included content objectives as well as attitudinal and behavioral objectives. Once these were established, it was possible to continue developing content and teaching strategies.

According to a meta-analysis that compared online pedagogies with those used in MOOCs, it was found that there are few differences, including use of short form videos, automated assessment, forums, and principles of retrieval and mastery learning [21]. This suggests that Faculty Development centers can translate existing expertise in online teaching to content design for MOOCs. In the Perspectives on Disability MOOC, this included designing online materials in short segments, structuring the course for easy access to materials, and identifying existing materials to supplement custom materials developed for the course. Given the preference for open access in a MOOC, finding and repurposing materials is often recommended [8], [9].

For MOOCs built on Connectivist principles, the focus of the course should be on building networks of individuals rather than an instructor delivering content, but analysis of previous courses reveals that students may be reluctant to engage in discourse with one another [5]. A "truly effective learning experience requires interactivity, communication, and community" [8]. MOOC design should include planning for participant interaction across multiple channels (e.g. formal, informal, social media, synchronous, asynchronous). At the same time, MOOC students value a strong instructor presence, which must be accounted for in the community.

Assessment has been a difficult topic for MOOCs because it is impossible, or at least difficult, for an instructor to provide detailed feedback on performance for thousands or students. In response, some MOOCs do not include assessments, particularly connectivist MOOCs that value interpersonal connections over content [22]. Some forego evaluating student work in favor of task-based or effort-based grading that awards "credit" for simply attempting the assessment or completing a series of tasks, regardless of the level of performance.

Many MOOCs use automated grading procedures, particularly for multiple choice or objective quizzes and exams. As adaptive testing systems that can incorporate all behavior and interactions within the course improve, this type of assessment will likely become popular in traditional courses, as well [15]. Given the size of student enrollment in most MOOCs, advanced item analysis techniques, such as scale linking and score equating, can be used to compare assess student performance while limiting the opportunity for cheating through techniques such as scale linking and score equating, which is not possible in smaller, classic assessment environments [23].

MOOCs have also been a fertile environment for experimenting with machine grading of traditionally subjective assessments, like writing assignments [15]. EdX, a nonprofit MOOC enterprise founded by Harvard and MIT, announced an automated system that uses artificial intelligence to grade student essays [24]. The instructor calibrates the system by scoring 100 essays, then the system's algorithm predicts the scoring and feedback for future essays. [25].

Although the technology is not new, acceptance for Automated Essay Scoring is still fairly low. Faculty who teach MOOCs are more positive about using peer grading for scoring writing assignments [15]. Peer grading introduces complexity due to the diversity of MOOC participants, given the range in educational backgrounds and native languages.

Whatever assessment techniques are adopted for a MOOC, it is important that they are established based on the desired learning outcomes. For the Perspectives on Disability MOOC, it made sense to connect assessments to real-world experience, since the course had a focus on changing attitudes and behaviors. The MOOC was also designed with Universal Design principles to be highly accessible [15], [26], so out of deference to the varied backgrounds and abilities of the participants, the assessments allow for multiple forms of expression.

Universal Design "involves designing products and spaces so that they can be used by the widest range of people possible" [27]. Since most MOOCs have large audiences, there is a strong likelihood of having students with disabilities who would benefit from accessible content, but all students can benefit, as well. Standard Universal Design practices for a MOOC would include captioning video content and posting transcripts for video and audio content.

There are many other aspects to designing and developing a MOOC, but in the authors' opinion, these are the most important areas where Faculty Development centers can assist faculty members who are building a MOOC. Other areas where Faculty Development centers may help with MOOC design include guiding the selection of technology for developing content (videos, screencasts, eBooks, etc.), providing institutional advice on the issue of offering credit for MOOCs, facilitating cultural change management within the institution, and preparing faculty to interact with diverse participants across countries and continents.

\section{MOOC Considerations}

Beyond typical course design considerations, there are additional aspects of designing and delivering a MOOC that may not have been encountered for traditional instruction. Faculty Development centers can provide leadership on these considerations.

The first aspect of MOOC delivery that is not typically addressed in traditional course delivery is to choose the technology platform for the MOOC, if there is not a formal partnership with a MOOC provider. The authors do not recommend for MOOCs to be delivered via the institution's learning management system (LMS) because of the overhead associated with increased use by a larger number of participants. This overhead can include creation and management of participant accounts, technical support for thousands of MOOC participants, and high demands on servers and bandwidth. In some cases, the solution is a combination of dedicated LMS installation, blogs, wikis, and social media [28]. Many options for cloud-based and open-source learning management systems or social tools are 
now available, and are well-suited for use in a MOOC. Faculty Development centers can research and stay up-to-date on technology solutions.

It is also important to consider factors affecting learner motivation and persistence in MOOCs. Low completion rates have been a frequent source of criticism. For example, Coursera, one MOOC provider, reported completion rates across courses of approximately 5\% [29]. Recent research has proposed looking at persistence as engagement trajectories, as learners move through phases of engagement and multiple channels of disengagement, which may inform design to increase engagement [30]. Research into persistence is also focusing on learner intent and motivation, and how both of those can impact retention [29]. Considering retention, persistence, and motivation will also influence evaluation plans and the selection of metrics to determine the value or success of a MOOC.

Funding is also a problem for MOOCs. Although MOOCs are usually free for the participants, the design, development, and videography required to produce one are not. The University of Pennsylvania reports that each MOOC they produce costs about $\$ 50,000$ [31], but that is not necessarily indicative of all MOOCs. Some may be funded through campus initiatives or partnerships, but that is not the case for all MOOCs. There are some grants available for MOOC development, particularly for developmental courses (an Internet search for "MOOC grant" returns a number of sources). It may also be possible to pursue contributions for MOOC development.

Once a MOOC is developed, to be truly massive it must be promoted effectively. For institutions that have partnered with a MOOC provider, this may be less important, as the MOOC providers have an audience and marketing strategy that will be able to attract participants. For others, promotion may require targeted email campaigns, social media presence, and institutional support. Although marketing may be an unfamiliar task for Faculty Development centers, it is an important corollary to determining the target audience for the MOOC. It may be possible to partner with the institution's media relations or marketing group to craft a stronger message and increase visibility. For the Perspectives on Disability MOOC, one of the target audiences included agencies that support persons with disabilities. As such, one facet of the promotion plan included sending an announcement about the course to such agencies via email. The MOOC also had a dedicated email address for inquiries and several social media accounts for socially-driven promotion. University Relations was able to assist with creating press releases and promoting the MOOC on institution social media accounts.

A final area of consideration that has become important in a MOOC that has not been as common in traditional courses is research. The body of research on MOOCs is growing, but there is still a need to study whether and how participants learn in a MOOC, whether learning outcomes are equivalent to those from traditional courses, and what practices or elements affect retention and persistence in completing the course. Although faculty members are accomplished researchers, some may not have experience with educational research. Faculty Development centers can encourage and guide research within MOOCs.

\section{CONCLUSION}

Massive open online courses have existed since 2008, but they are really still in their infancy as a mode of education and have captured the attention of higher education and the public. Many institutions launched MOOCs very quickly, but others have yet to develop or deliver a MOOC. Daunting as it may seem, developing a MOOC is still similar to designing and developing a traditional course, and institutions would benefit from consulting with Faculty Development centers for guidance with these initiatives.

MOOCs are somewhat different from general online courses, and require additional considerations. Before planning a MOOC, Faculty Development centers should participate in multiple MOOCs to gain perspective, research the emerging learning theories that the MOOC phenomenon grew from, and research the legal issues that are present in MOOCs. While designing the course, faculty members would benefit from guidance on choosing a topic and determining whether there is an audience, building a team to develop and deliver the course, planning the development process, designing the course, planning for community development within the course, and assessing a massive audience. Finally, there are some aspects of MOOC design and delivery that may be unfamiliar to Faculty Development centers and faculty members alike, but are important nonetheless, including selecting technology to support a MOOC, seeking funding, promoting the course, dealing with legal issues, and researching the learning that occurs in the MOOC.

MOOCs may revolutionize higher education, or they may be a passing fad. In either case, MOOCs are currently playing a significant role in institutions of higher education, and cannot be ignored.

\section{ACKNOWLEDGMENT}

The authors would like to express their sincere gratitude to Tracy Miller (Online Teaching Coordinator at the Faculty Development and Instructional Design Center), Gregory Long (Presidential Teaching Professor, School of Allied Health and Communicative Disorders), Gregory Brady (University Legal Services), Paul Palian (Media Relations and Internal Communications), the Office of the Provost, College of Health and Human Sciences, and the Department of Communication at Northern Illinois University, and Jarl Jonas and Sarah Bishop-Root of Blackboard Course Sites for their contributions to the authors' MOOC research and experience.

\section{REFERENCES}

[1] R. Nilsson. (May 2013). Trends in massive open online courses [Online]. Available: http://blogs.enterasys.com/trends-in-massive-open-online-courses-inf ographic/

[2] L. Pappano. (November 2012). Massive open online courses are multiplying at a rapid pace. The New York Times. [Online]. Available: http://www.nytimes.com/2012/11/04/education/edlife/massive-open-o nline-courses-are-multiplying-at-a-rapid-pace.html

[3] A. Watters. (December 2012). Top ed-tech trends of 2012: MOOCs [Online].

Available: http://www.insidehighered.com/blogs/hack-higher-education/top-ed-t ech-trends-2012-moocs

[4] L. Johnson, S. A. Becker, M. Cummins, V. Estrada, A. Freeman, and H. Ludgate. (2013). NMC horizon report: 2013 Higher education edition. 
Austin, Texas: The New Media Consortium. [Online]. Available: http://www.nmc.org/pdf/2013-horizon-report-HE.pdf

[5] D. Cormier and G. Siemens, "Theopen course: Through the open door--Open courses as research, learning, and engagement. EDUCAUSE Review," vol. 45, no. 4, pp. 30-39, 2010.

[6] S. Downes. (April 2009). New technology supporting informal learning. [Online]. Available:http://halfanhour.blogspot.com/2009/04/new-technology-su pporting-informal.html

[7] What you need to know about MOOCs. The Chronicle of Higher Education. [Online]. Available: http://chronicle.com/article/What-You-Need-to-Know-About/133475/

[8] T. Joosten. (April 2013). Ten questions for MOOC design. [Online]. Available:

http://professorjoosten.blogspot.com/2013/04/ten-questions-for-mooc -design.html

[9] G. Siemens. (September 2012). Designing and running a MOOC (in 9 easy $\quad$ steps). [Online]. Available: http://www.elearnspace.org/blog/2012/09/04/designing-and-running-a -mooc-in-9-easy-steps/

[10] G. Siemens, "Connectivism: A learning theory for the digital age," International Journal of Instructional Technology \& Distance Learning, vol. 2, no. 1, January 2005.

[11] I. de Waard, S. Abajian, M. S. Gallagher, R. Hogue, N. Keskin, A. Koutropoulos, and O. C. Rodriguez, "Using mLearning and MOOCs to understand chaos, emergence, and complexity in education," The International Review of Research in Open and Distance Learning, vol. 12, no. 7, pp. 94-115, 2011.

[12] S. Kolowich. (May 2013). Faculty backlash grows against online partnerships. The Chronicle of Higher Education. [Online]. Available: http://chronicle.com/article/Faculty-Backlash-Grows-Against/139049/

[13] J. Lawrence. (April 2013). UC Berkeley faculty association comes out against MOOC bill. Education News. [Online]. Available: http://www.educationnews.org/online-schools/uc-berkeley-faculty-ass ociation-comes-out-against-mooc-bill/

[14] NIU professor crafts disability MOOC. (July 2013). NIU Today. [Online]. Available: http://www.niutoday.info/2013/07/09/96319/

[15] C. Sandeen, "Assessment's place in the new MOOC world," Research \& Practice in Assessment, vol. 8, no. 2, pp. 5-12, 2013.

[16] S. M. Morris and J. Strommel. (2012). MOOC. [Online]. Available: http://moocmooc.com/

[17] K. Cennamo and D. Kalk, Real world instructional design, Belmont, CA: Thomson Wadsworth, 2005.

[18] Y. Belanger and J. Thornton. (2013). Bioelectricity: A Quantitative Approach. Duke University. [Online]. Available: http://dukespace.lib.duke.edu/dspace/bitstream/handle/10161/6216/D uke_Bioelectricity_MOOC_Fall2012.pdf

[19] T. Balch. (January 2013). MOOC student demographics. The augmented trader. [Online]. Available: http://augmentedtrader.wordpress.com/2013/01/27/mooc-student-dem ographics/

[20] S. Kolowich. (June 2012). Early demographic data hints at what type of student takes a MOOC. Inside Higher Ed. [Online]. Available: http://www.insidehighered.com/news/2012/06/05/early-demographicdata-hints-what-type-student-takes-mooc

[21] D. G. Glance, M. Forsey, and M. Riley. (May 2013). The pedagogical foundations of massive open online courses. First Monday. [Online] Available: http://firstmonday.org/ojs/index.php/fm/article/view/4350

[22] S. Downes. (May 2013). Assessment in MOOCs. Half an hour. [Online]. Available: http://halfanhour.blogspot.com/2013/05/assessment-in-moocs.html

[23] J. P. Meyer and S. Zhu, "Fair and equitable measurement of student learning in MOOCs: An introduction to item response theory, scale linking, and score equating," Research \& Practice in Assessment, vol. 8, no. 2, pp. 26-39, 2013.

[24] J. Markoff. (April 2013). Essay-grading software offers professors a break. The New York Times. [Online]. Available: http://www.nytimes.com/2013/04/05/science/new-test-for-computersgrading-essays-at-college-level.html

[25] S. P. Balvour, "Assessing writing in MOOCs: Automated essay scoring and calibrated peer review ${ }^{\mathrm{TM}}, "$ Research \& Practice in Assessment, vol. 8, no. 2, pp. 40-48, 2013.

[26] The seven principles of universal design. (2013). UniversalDesign.com. [Online]. Available: http://www.universaldesign.com/universal-design/1761-the-seven-pri nciples-of-universal-design.html

[27] What is universal design? (2013). UniversalDesign.com. [Online]. Available:

http://www.universaldesign.com/about-universal-design.html

[28] A. Fini, "The technological dimension of a massive open online course: The case of the CCK08 course tools," The International Review of Research in Open and Distance Learning, vol. 10, no. 5, 2009.

[29] D. Koller, A. Ng, C. Do, and Z. Chen, "Retention and intention in massive open online courses: In depth," Educause Review, vol. 48, no. 3, June 2013.

[30] R. F. Kizilcec, C. Piech, and E. Schneider, "Deconstructing disengagement: analyzing learner subpopulations in massive open online courses," in Proc. the Third International Conference on Learning Analytics and Knowledge, New York, NY, USA, 2013, pp. 170-179.

[31] T. Popp. (March 2013). MOOC U. The Pennsylvania Gazette. [Online]. 111(4). http://www.upenn.edu/gazette/0313/feature4_1.html

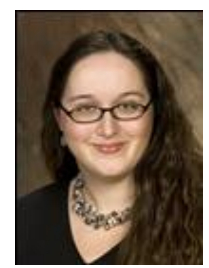

Stephanie L. Richter is currently pursuing an Ed.D in instructional technology in the Department of Educational Technology, Research, and Assessment at Northern Illinois University (NIU) in DeKalb, IL, U.S.A. She received a master's degree in instructional technology in 2006 and a bachelor's of science in mathematics education in 2003, both from NIU.

She is the assistant director of the Faculty Development and Instructional Design Center at NIU. Previously, she was the Instructional Technologies Coordinator for the same department. Before coming to NIU, she was a Project Manager and Senior Instructional Designer with Centrax Corporation in Chicago, IL.Her research interests include learning management systems, mobile learning, MOOCs, and online teaching.

Ms. Richter is a member of the Association for Educational Communications and Technology (AECT), and the Supporting Learning and Technology in Education (SLATE) Group. She received the 2013 Blackboard Key to the Community Award, and the 2011 NIU Supportive Professional Staff Certificate of Recognition. She is also the recipient of the 2011 SLATE Star Award with staff of the Faculty Development and Instructional Design Center.

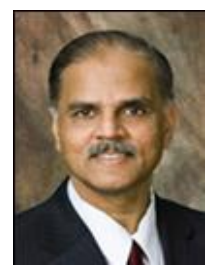

Murali Krishnamurthi received a bachelor's degree in mechanical engineering in 1978 from University of Madras, a master's degree in industrial and systems engineering in 1982 from Ohio University, and a doctorate in industrial engineering in 1988 from Texas A\&M University.

$\mathrm{He}$ is a professor of Industrial and Systems Engineering and Associate Provost for Academic Technologies and Faculty Development at Northern Illinois University in DeKalb, Illinois, U.S.A. His teaching and research interests include project management, information systems, system simulation, optimization techniques, faculty development, and distance learning.

Dr. Krishnamurthi is a member of the American Association for Engineering Education (ASEE) and the Professional and Organization and Development (POD) Network. He received the Presidential Teaching Professor Award and the Deacon Davis Diversity award in 2011. 